\title{
Prevalence and association of dyslipidemia with diabetic and hypertension in population of Takht-e-Nasrati, Khyber Pakhtunkhwa, Pakistan
}

Ayesha Rizwan ${ }^{1}$, Sobia Attaullah², Muhammad Jawad ${ }^{2 *}$, Faheem Ullah ${ }^{3}$, Muhammad Zahid ${ }^{2}$, Faisal Saeed ${ }^{2}$, Abdul Wahab ${ }^{2}$ and Usama Siddique ${ }^{4}$

1. Department of Zoology, University of Peshawar, Khyber Pakhtunkhwa, Pakistan

2. Department of Zoology, Islamia College Peshawar, Khyber Pakhtunkhwa, Pakistan

3. Type C Hospital Takht-e-Nasrati Karak, Khyber Pakhtunkhwa, Pakistan

4. Institute of Nursing Sciences, Khyber Medical University, Peshawar, Khyber Pakhtunkhwa, Pakistan

*Corresponding author's email: jawadktk1293@gmail.com

Citation

Ayesha Rizwan, Sobia Attaullah, Muhammad Jawad, Faheem Ullah, Muhammad Zahid, Faisal Saeed, Abdul Wahab and Usama Siddique. Prevalence and association of dyslipidemia with diabetic and hypertension in population of Takht-e-Nasrati, Khyber Pakhtunkhwa, Pakistan. Pure and Applied Biology. Vol. 11, Issue 3, pp696-703. http://dx.doi.org/10.19045/bspab.2022.110070

Received: 30/07/2021 Revised: 20/09/2021

Accepted: 25/09/2021

Online First: 07/10/2021

\section{Abstract}

This research aims to study the prevalence rate of dyslipidemia and its association with diabetics and hypertension among different gender in a population of Takht-e-Nasrati, Khyber Pakhtunkhwa, Pakistan. Analysis of the different levels of cholesterol and lipoprotein were also studied. A total of 200 individuals were evaluated for their blood lipid profiles during their visits to the laboratory. Participants who had a blood pressure of more than 140/90 $\mathrm{mmHg}$ were classified as hypertensive. Diabetic patients, on the other hand, were selected based on fasting blood glucose levels greater than $126 \mathrm{mg} / \mathrm{dl}$ and HbA1c values larger than 6.5 percent. SPSS-21 was used to collect and analyze the data for the Chi-square test. The result of the current study shows that a high prevalence rate of dyslipidemia $110(56 \%)$ were found in male as compared to female 90 $(44 \%)$ out of a total of 200 individuals. A high prevalence rate of dyslipidemia $92(46 \%)$ were found in age group III. Hypertension 79 (64\%) were the most prevalent associated factor in dyslipidemia individuals followed by diabetic 44 (36\%). HDL cholesterol levels were high 89 $(46 \%)$ in male and $72(36 \%)$ in female. Low levels of total cholesterol $82(41 \%)$ in male and 70 $(35 \%)$ in female were studied. Diabetes and hypertension are both linked to dyslipidemia. To avoid the development of cardiovascular diseases, diabetic and hypertensive individuals with dyslipidemia should be closely monitored.

Keywords; Association; Diabetics; Dyslipidemia; Hypertension; Prevalence; Takht-e-Nasrati

Introduction

All around the world, cardiovascular disorders represent the major cause of morbidity and mortality [1]. Previously prevalent in a relatively wealthy society, these diseases are currently reported to be declining in high-income countries while 
rapidly growing in many middle and lowincome countries [2].

These shifting proportions of the burden of cardiovascular disease are observed along with a general epidemiological transition of the burden of disease from predominantly communicable to non-communicable diseases (NCDs), which has been observed globally, in parallel with social change and economic development [3]. The Eastern Mediterranean region's disease burden from NCDs is expected to rise from 46 percent in 2004 to 60 percent by 2020, with dyslipidemia prevalence approaching 50 percent in some areas [4].

Dyslipidemia is an abnormally high level of non-high density lipoprotein cholesterol (HDL-C) in the body. It has been observed that dyslipidemia is strongly associated with other metabolic diseases like hypertension and diabetes. In addition, these three diseases further contribute to the development of atherosclerotic heart diseases [5].

The overall burden of atherosclerotic diseases is on the rise worldwide [6]. Controlling risk factors for cardiovascular diseases will eventually lead to decreased mortality. If one knew about the prevalence of dyslipidemia in hypertensive and diabetic patients, there would be fewer mortalities as better strategies could be designed to cope with the problem [7].

The onset and progression of dyslipidemia is typically a long-term, ongoing process $[8,9]$. Distinct factors may play different roles in the progression of dyslipidemia. Different provinces and areas have done previous studies on dyslipidemia and associated variables [10-12]. Although studies have found an association between dyslipidemia, hypertension and diabetes mellitus, the data from the South Asian population from an epidemiological point of view is scant and large-scale investigations into the population of Takht-e-Nasrati, District Karak, are scarce. We attempted to determine the prevalence of dyslipidemia in the population of Takht-e-Nasrati, Khyber Pakhtunkhwa, Pakistan, in this study. The goal of the research was to investigate the prevalence of dyslipidemia in diabetic and hypertensive patients.

\section{Materials and Methods \\ Study area}

The study lasted nine months, from September 2019 to May 19, 2020, in population of Takht-e-Nasrati at Type "C" Hospital in Takht-e-Nastrati, Distract Karak, Khyber Pakhtunkhwa (KPK), Pakistan.

\section{Data collection}

A total of 200 individuals were evaluated for lipid profiles and their blood lipid profiles during their visits to the laboratory. This study included patients who were 25 years old or older at the time of their visit and enrolment in the lab.

\section{Study methodology}

Personal data, including name, gender, and age, and history of disease type and clinical symptoms of lipid disorder were recorded through a questionnaire. After the recording of personal data, the individuals were then instructed to fast for at least 8 hours the next morning before undergoing venous blood sampling. A second visit was done the morning after the first visit between seven and nine o'clock. Following confirmation that participants in the study fasted for at least 8 hours overnight, their blood pressure was taken while they sat in a validated protocol with a sphygmomanometer. For blood sugar and cholesterol levels, a fasting venous blood sample of $5 \mathrm{~mL}$ was obtained. Participants were recorded with validated techniques for anthropometric measurements, including height, weight, and circumference of the waist.

\section{Biochemical analysis of sample}

For different cholesterol readings, blood samples were obtained and examined on a Beckman Coulter AU680 Chemistry Analyzer. An automated chemistry 
laboratory technician analyzed plasma lipid levels. Analyses of lipid disorders were based on the following conditions: high total cholesterol (TC) (more than $240 \mathrm{mg} / \mathrm{dl}$ ), high triglycerides (TG) (more than $200 \mathrm{mg} / \mathrm{dl}$ ), high Low-density lipoproteins (LDL) (more than $130 \mathrm{mg} / \mathrm{dl}$ ), and low high-density lipoproteins (HDL) (less than $40 \mathrm{mg} / \mathrm{dl}$ ). The (Table 1a, b) show the technique for measuring cholesterol, triglycerides, and
HDL using a kit. All of the individuals have either hypertension or diabetes. Participants who had a blood pressure of more than 140/90 mmHg were classified as hypertensive. Diabetic patients, on the other hand, were chosen because their fasting blood glucose levels were greater than 126 $\mathrm{mg} / \mathrm{dl}$ and their HbA1c values were greater than 6.5 percent. SPSS-21 was used to collect and analyses the data for the Chi-square test.

Table 1a, b. Showing kit protocol for Cholesterol, triglycerides and HDL

\begin{tabular}{|c|c|c|c|c|c|}
\hline \multicolumn{2}{|c|}{ a } & \multicolumn{3}{|c|}{ b } \\
\hline Reagent & STD & Test Tube & Reagent & STD & Test Tube \\
\hline R1 & $1000 \mu 1$ & $1000 \mu 1$ & R1 & $500 \mu l$ & $500 \mu 1$ \\
\hline Sample & $\mathrm{x}$ & $100 \mu 1$ & STD & $200 \mu 1$ & $\mathrm{x}$ \\
\hline STD & $100 \mu \mathrm{l}$ & $\mathrm{x}$ & Sample & $\mathrm{x}$ & $200 \mu \mathrm{l}$ \\
\hline
\end{tabular}

\section{Results}

A total of 200 individuals who had dyslipidemia were included in this study. Out of 200 individuals, 110 (55\%) were male and $90(45 \%)$ were female. Male show a high rate of prevalence as compared to female (Fig. 1; Table 2).

The prevalence of dyslipidemia was also studied among different age groups of participating individuals. The minimum age of 25 years and the maximum age of 60 years were reported in this study. The mean age of all the study population were 42.05 years. Individuals are divided into four age groups; group I contains individuals having an age of 29, group II (30-39), group III (40-49), and group IV ( $>50$ ) years. Out of a total of 200 individuals, a high rate of prevalence of 92 $(46 \%)$ were found in group III, followed by $50(25 \%)$ in group IV, $47(23 \%)$ in group II and $11(6 \%)$ in group I (Fig. 2; Table 3).

Individuals were also distributed on the basis of association of dyslipidemia with diabetics and hypertension. Of the total 200 individuals, $123(60 \%)$ have diabetic and hypertension. The prevalence rate of hypertension were greater $79(64 \%)$ in individuals having dyslipidemia and 44
(36\%) have diabetic disease (Fig. 3; Table $4)$.

A gender-wise distribution of diabetics and hypertensive diseases was also studied. Out of 200 individuals, $123(61 \%)$ have diabetic and hypertension diseases, in which 44 (36\%) individuals have diabetic and $79(64 \%)$ have hypertension. Gender wise prevalence were checked in this study, showing a high prevalence rate of 31 (70) of diabetics in male as compared to female $13(30 \%)$ out total 44 individuals. The prevalence rate of hypertension were also high at $42(53 \%)$ in male as compared to female $37(47 \%)$ out of 79 patients (Fig. 4; Table 5).

In the current study, various cholesterol level were also checked among the genders having dyslipidemia. Both high, normal and low levels of total cholesterol, HDL, LDL, and triglycerides were checked in both male and female. HDL cholesterol level were high 89 $(46 \%)$ in male and $72(36 \%)$ in female. Low level of total cholesterol of $82(41 \%)$ in male and $70(35 \%)$ in female were studied, confirming that HDL cholesterol levels remained high and total cholesterol levels remained low in individuals having dyslipidemia (Table 6). 


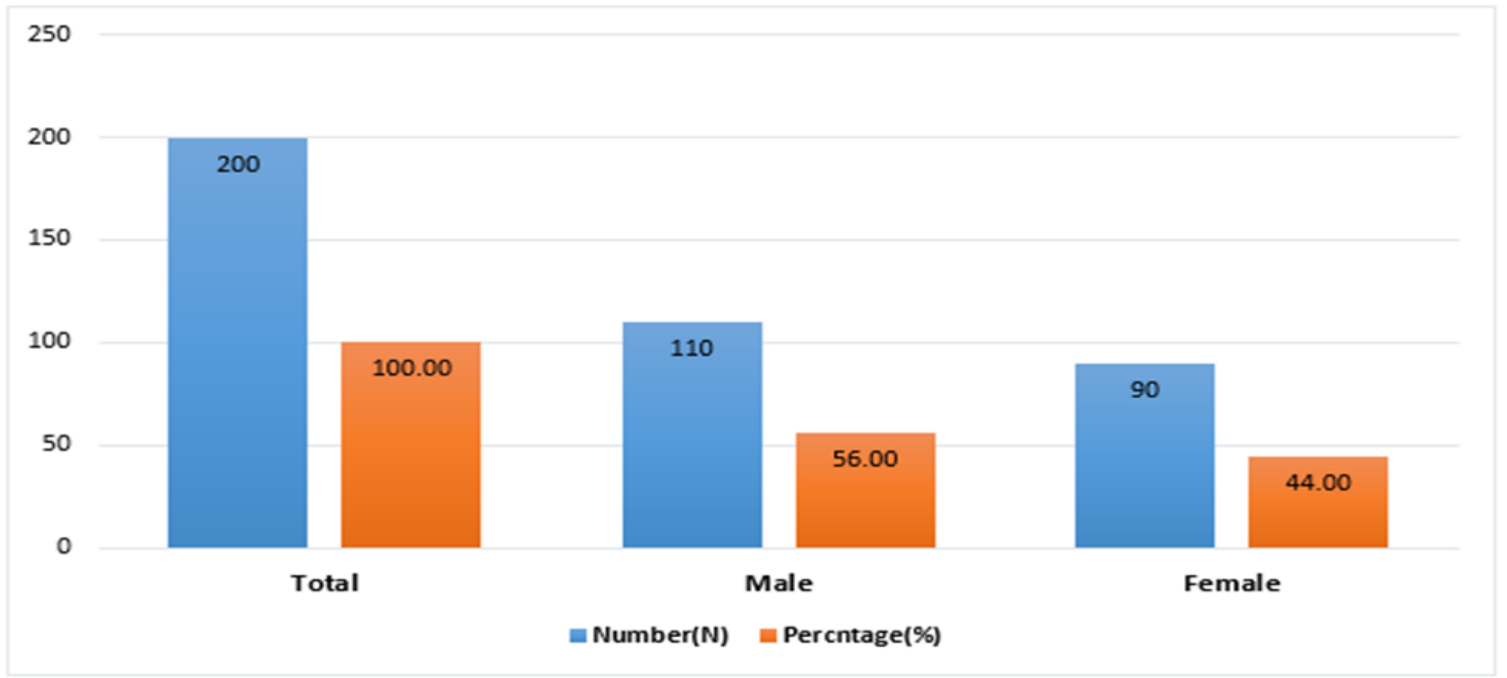

Figure 1. Showing gender wise Prevalence of Dyslipidemia disease

Table 2. Gender wise distribution of Dyslipidemia

\begin{tabular}{|c|c|c|}
\hline Variable & Number $(\mathbf{N})$ & Percentage(\%) \\
\hline Male & 110 & 55 \\
\hline Female & 90 & 45 \\
\hline Total & 200 & 100 \\
\hline
\end{tabular}

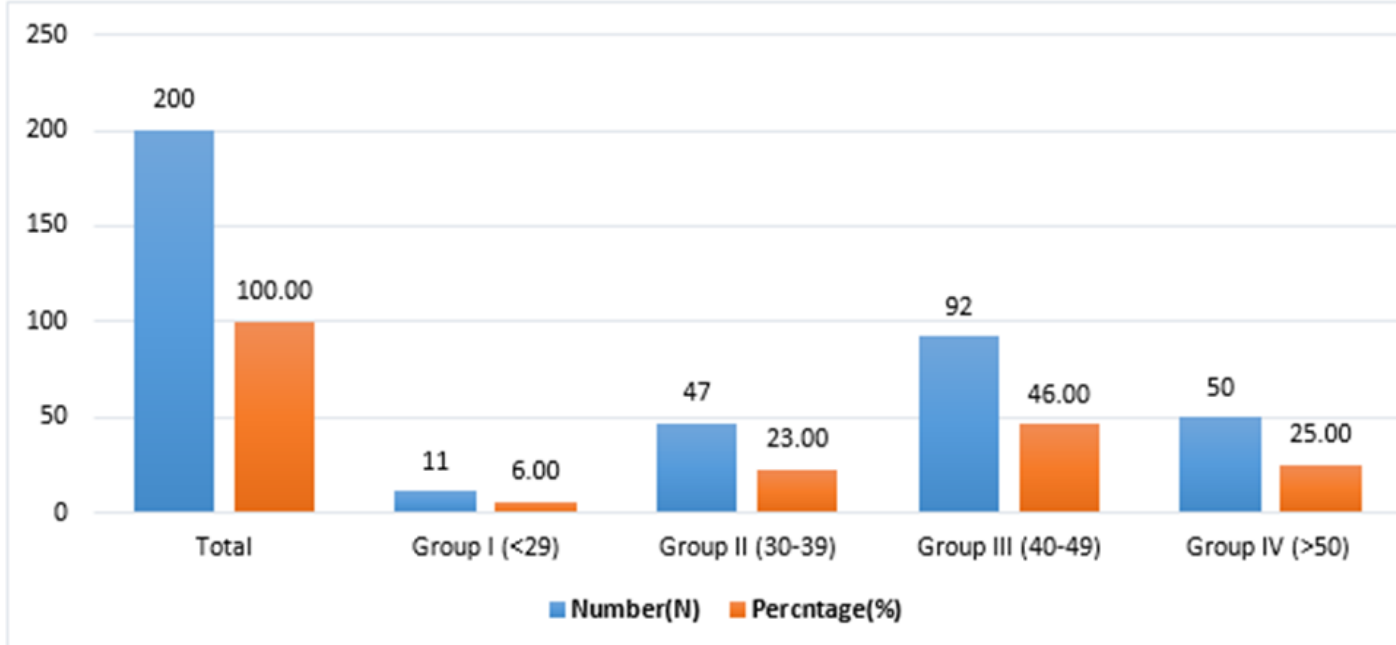

Figure 2. Showing Age wise prevalence of Dyslipidemia disease

Table 3. Distribution of Dyslipidemia disease according to different Age groups

\begin{tabular}{|c|c|c|}
\hline Variable & Number (N) & Percentage (\%) \\
\hline Group I: $<29$ & 11 & 6 \\
\hline Group II:30-39 & 47 & 23 \\
\hline Group III:40-49 & 92 & 46 \\
\hline Group IV: $>50$ & 50 & 25 \\
\hline Total & 200 & 100 \\
\hline
\end{tabular}




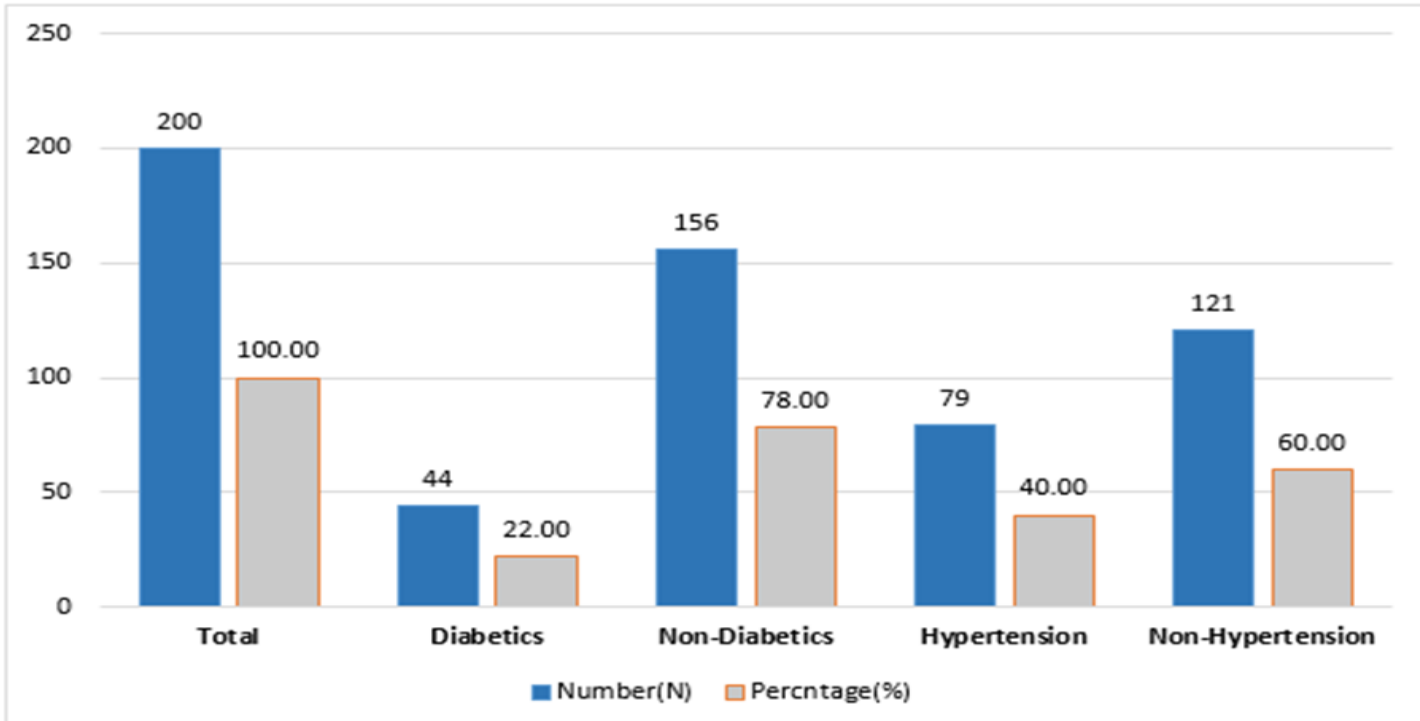

Figure 3. Showing Prevalence of Dyslipidemia association with Diabetic and Hypertension

Table 4. Distribution of Diabetics and Hypertension patients

\begin{tabular}{|c|c|c|c|}
\hline \multicolumn{2}{|c|}{ Variable } & Number (N) & Percentage(\%) \\
\hline \multirow{2}{*}{ Diabetics } & Diabetics & 44 & 22 \\
\cline { 2 - 4 } & Non-Diabetics & 156 & 78 \\
\hline \multirow{2}{*}{ Total } & $\mathbf{2 0 0}$ & $\mathbf{1 0 0}$ \\
\hline \multirow{2}{*}{ Hypertension } & Hypertension & 79 & 40 \\
\cline { 2 - 4 } & Non-Hypertension & 121 & 60 \\
\hline \multicolumn{2}{|c|}{ Total } & $\mathbf{2 0 0}$ & $\mathbf{1 0 0}$ \\
\hline
\end{tabular}

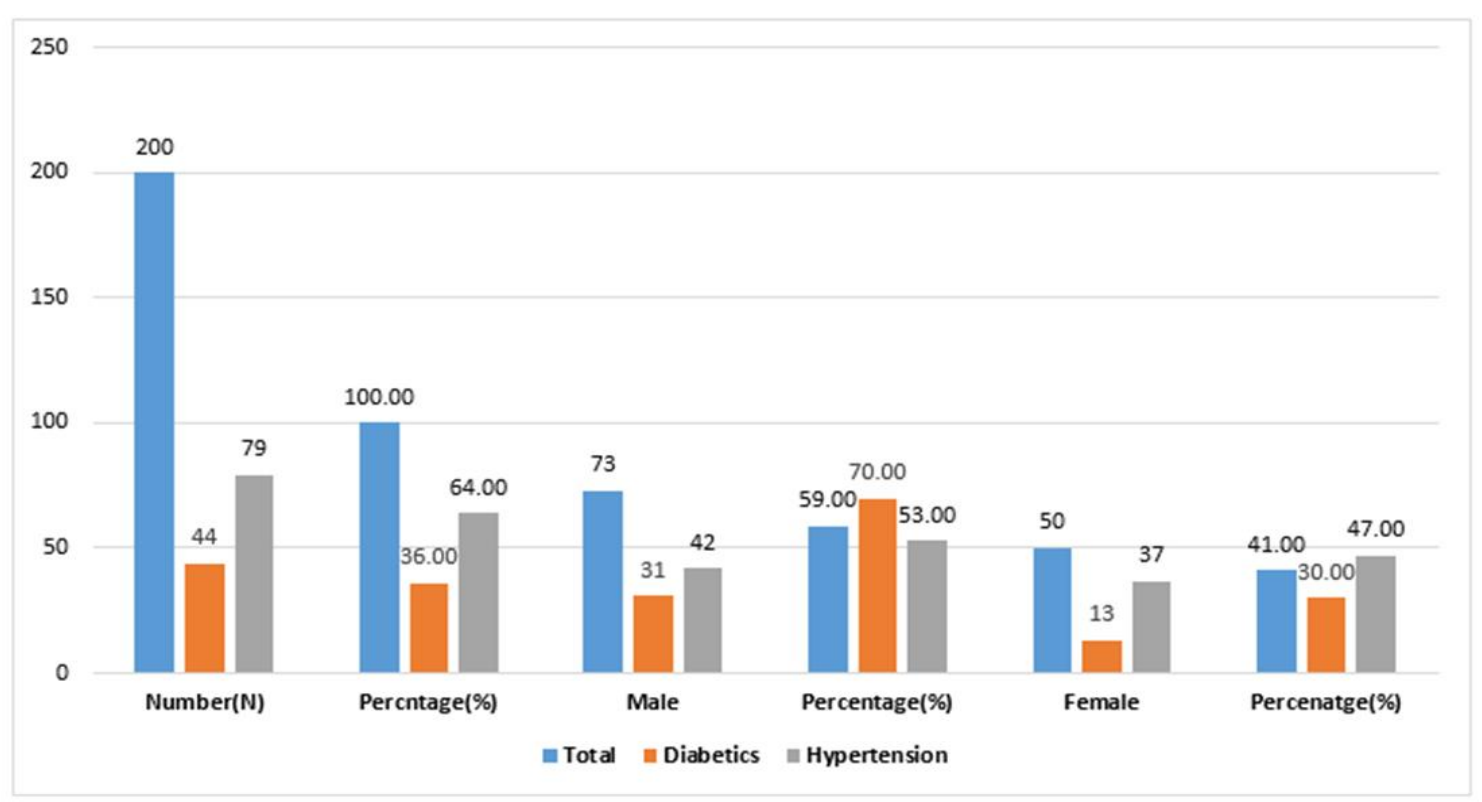

Figure 4. Showing gender wise prevalence of diabetic and Hypertension 
Table 5. Gender Wise distribution of Dyslipidemia on basis of Diabetics and Hypertension

\begin{tabular}{|c|c|c|c|c|c|c|}
\hline Variable & Number $(\mathbf{N})$ & $(\boldsymbol{\%})$ & Male & $\mathbf{( \% )}$ & Female & $(\boldsymbol{\%})$ \\
\hline Diabetics & 44 & 36 & 31 & 70 & 13 & 30 \\
\hline Hypertension & 79 & 64 & 42 & 53 & 37 & 47 \\
\hline Total & 123 & 100 & 73 & 59 & 50 & 41 \\
\hline
\end{tabular}

Table 6. Level of various cholesterol lipoprotein in gender

\begin{tabular}{|c|c|c|c|c|c|c|}
\hline \multirow{2}{*}{ Variable } & \multicolumn{3}{|c|}{ Male (N\%) } & \multicolumn{3}{c|}{ Female (N\%) } \\
\cline { 2 - 7 } & High & Normal & Low & High & Normal & Low \\
\hline Total Cholesterol & $22(11)$ & $6(3)$ & $82(41)$ & $14(7)$ & $6(3)$ & $70(35)$ \\
\hline HDL Cholesterol & $89(46)$ & $8(4)$ & $13(7)$ & $72(36)$ & $8(4)$ & $10(5)$ \\
\hline LDL Cholesterol & $28(11)$ & $47(24)$ & $35(18)$ & $20(10)$ & $52(26)$ & $18(9)$ \\
\hline Triglycerides & $31(16)$ & $79(40)$ & 0 & $23(12)$ & $67(34)$ & 0 \\
\hline
\end{tabular}

\section{Discussion}

In cardiovascular disease, hypertension, diabetes and dyslipidemia and disordered lipid profiles play a significant role. The purpose of this study was to assess the prevalence of dyslipidemia and its relationship to diabetic and hypertensive individuals in the Takht-e-Nasrati, Khyber Pakhtunkhwa, Pakistan population. A high prevalence rate of dyslipidemia was found in the male population at $110(\%)$ as compared to the female having prevalence rate $90(\%)$ out of a total of 200 individuals. A recent study conducted by Agerwal et al., 2014 on gender and age wise observation of dyslipidemia showed a high rate of prevalence of $154(50 \%)$ in male as compared to the opposite gender [13]. A high prevalence rate of dyslipidemia was found in male individuals as compared to female [14, 15].

Current research also observed age-wise prevalence of dyslipidemia. The minimum age of 25 years and the maximum age of 60 years were reported in this study. The mean age of all the study population were 42.05 years. Individuals are divided into four age groups. Of the total 200 individuals, the highest prevalence rate of dyslipidemia 92 $(46 \%)$ were found in group III, followed by $50(25 \%)$ in group IV, $47(23 \%)$ in group II and $11(6 \%)$ in group I. Our study shows similar findings with other studies showing the highest prevalence rate in the $>40$ age group [16-18].

The prevalence of dyslipidemia in diabetics and hypertension among different genders of individuals were also studied in the studied population. Of 200 individuals, 123 (60\%) have both diabetic and hypertension disorders. The prevalence rate of hypertension was greater $79(64 \%)$ in individuals with dyslipidemia and in 44 (36\%) of those with diabetic disease. A recent study conducted by Zubair et al., 2020 also shows similar results to our study. The prevalence of dyslipidemia in hypertension patients was high: $71.6 \%$, followed by $68.1 \%$ in diabetic patients [19]. Gender-wise prevalence was checked in this study, showing a high prevalence rate of $31(70 \%)$ of diabetics in male as compared to female 13 $(30 \%)$ out total 44 individuals. The prevalence rate of hypertension was also high at $42(53 \%)$ in male as compared to $37(47 \%)$ in females out of 79 patients. Dyslipidemia was shown to be prevalent in hyperglycemic individuals in $89 \%$ and $92.4 \%$ of two investigations conducted in India $[14,20]$. In diabetic patients, the prevalence of dyslipidemia was 99.13 percent in males and 89.14 percent in females, but in Jayarama's study, it was 95.40 percent and 86.75 percent for male and female, respectively [14].

In the current study, various cholesterol levels were also checked among the genders 
having dyslipidemia. Both high, normal and low levels of total cholesterol, HDL, LDL and triglycerides were checked in both male and female. HDL cholesterol level were high $89(46 \%)$ in male and $72(36 \%)$ in female. Low levels of total cholesterol of $82(41 \%)$ in male and $70(35 \%)$ in female were studied, confirming that HDL cholesterol levels remained high and total cholesterol levels remained low in individuals having dyslipidemia. Our study shows persistence with other studies [18, 21-23].

\section{Conclusion}

The result of the current study concluded that a high prevalence rate of dyslipidemia was found in the studied population. The current study also shows the alarming situation of dyslipidemia and its association with diabetics and hypertension. The main causes of the high prevalence of metabolic diseases were physical inactivity and a high-fat diet. To broaden the scope of metabolic illnesses in the region, more detailed research is needed.

\section{Authors' contributions}

Conceived and designed the experiments: A Rizwan \& S Attaullah. Performed the experiments: A Rizwan, M Jawad, A Wahab, F Saeed \& U Siddique. Analyzed the data: M Zahid \& F Ullah. Contributed reagents/ materials/ analysis tools: M Jawad, A Rizwan \& F Ullah, Wrote the paper: M Jawad.

\section{Acknowledgment}

The authors are thankful to Assistant Prof. Dr. Sobia Attaullah, Department of Zoology, Islamia College, Peshawar, KPK, for helping and designing the experimental work. The authors are also thankful to Dr. Faheem Ullah, Medical Officer, Type "C" Hospital, Takht-e-Nasrati, District Karak, PKP, Pakistan for helping during data collection and lab work.

\section{References}

1. Mathers CD, Lopez AD \& Murray CJ (2006). The burden of disease and mortality by condition: data, methods, and results for 2001. Glob Burden of Dis and Risk Fact 45: 88.

2. Murray CJ \& Lopez AD (1997). Alternative projections of mortality and disability by cause 1990-2020: Global Burden of Disease Study. The Lanc 349(9064): 1498-1504.

3. Yusuf S, Reddy S, Ônpuu S \& Anand S (2001). Global burden of cardiovascular diseases: Part II: variations in cardiovascular disease by specific ethnic groups and geographic regions and prevention strategies. Circul 104(23): 2855-2864.

4. Khatib O (2004). Non communicable diseases: risk factors and regional strategies for prevention and care. EMHJ-Eastern Mediter Health J 10(6): 778-788.

5. Otsuka T, Takada H, Nishiyama $Y$, Kodani E, Saiki Y, Kato K \& Kawada T (2016). Dyslipidemia and the risk of developing hypertension in a workingage male population. $J$ of the Am Heart Ass 5(3): 003053.

6. Boo S, Yoon YJ \& Oh H (2018). Evaluating the prevalence, awareness, and control of hypertension, diabetes, and dyslipidemia in Korea using the NHISNSC database: A cross-sectional analysis. Medi 97(51).

7. Dalal JJ, Padmanabhan TNC, Jain P, Patil S, Vasnawala H \& Gulati A (2012). LIPITENSION: Interplay between dyslipidemia and hypertension. Indian $J$ of Endo and Metab 16(2): 240.

8. Sharma U, Kishore J, Garg A, Anand T, Chakraborty M \& Lali P (2013). Dyslipidemia and associated risk factors in a resettlement colony of Delhi. $J$ of Clin Lipidol 7(6): 653-660.

9. Rodriguez CJ, Daviglus ML, Swett K, González HM, Gallo LC, WassertheilSmoller S \& Kaplan RC (2014). Dyslipidemia patterns among Hispanics/Latinos of diverse background 
in the United States. The $A m \quad J$ of Med 127(12): 1186-1194.

10. He H, Yu YQ, Li Y, Kou CG, Li B, Tao YC \& Liu YW (2014). Dyslipidemia awareness, treatment, control and influence factors among adults in the Jilin province in China: a cross-sectional study. Lipids in Health and Dis 13(1): 19.

11. Shi L, Hu J, Zhu K, Fu Y, Xia R, \& Hu X (2014). Changes of prevalence of dyslipidemia among adults: a cross-sectional study with a 2-year follow-up in urban southeast China. Clin Lipidology 9(1): 33-47.

12. Wang M, Hou X, Hu W, Chen L \& Chen S (2019). Serum lipid and lipoprotein levels of middle-aged and elderly Chinese men and women in Shandong Province. Lipids in Health and Dis 18(1): 1-8.

13. Hamid SM \& Shani WS (2018). The association of IL-10 (-592A/C) gene polymorphism with progression of Type 2 Diabetes Mellitus in Basrah ProvinceIraq. Iraqi J of Scie 59(2B): 819-826.

14. Jayarama N, Reddy M \& Lakshmaiah V (2012). Prevalence and pattern of dyslipidemia in type 2 diabetes mellitus patients in a rural tertiary care center, southern India. Glob J Med Pub Health 1: 24-8.

15. Joshi SR, Anjana RM, Deepa M, Pradeepa R, Bhansali A, Dhandania VK \& ICMR-INDIAB Collaborative Study Group (2014). Prevalence of dyslipidemia in urban and rural India: the ICMR-INDIAB study. PloS One 9(5): 96808.
16. Scheidt-Nave C, Du Y, Knopf H, Schienkiewitz A, Ziese T, Nowossadeck E \& Busch M (2013). Prevalence of dyslipidemia among adults in Germany.

17. Xi Y, Niu L, Cao N, Bao H, Xu X, Zhu H $\&$ Zhang $X$ (2020). Prevalence of dyslipidemia and associated risk factors among adults aged $\geq 35$ years in northern China: a cross-sectional study. BMC Pub Health 20(1): 1-9.

18. Sarfraz M, Sajid S \& Ashraf MA (2016). Prevalence and pattern of dyslipidemia in hyperglycemic patients and its associated factors among Pakistani population. Saudi J of Biol Sci 23(6): 761-766.

19. Sharma U, Kishore J, Garg A, Anand T, Chakraborty M \& Lali P (2013). Dyslipidemia and associated risk factors in a resettlement colony of Delhi. $J$ of Clin Lipidol 7(6): 653-660.

20. Zubair M, Waqar S, Abid S, Haider A \& Kamran S (2020). Prevalence of dyslipidemia in hypertensive and diabetic patients. Pak J of Phy 16(2): 38-40.

21. Udawat H, Goyal RK \& Maheshwari S (2001). Coronary risk and dyslipidemia in type 2 diabetic patients. The $J$ of the Ass of Phys of India 49: 970-973.

22. Al-Adsani A, Memon A \& Suresh A (2004). Pattern and determinants of dyslipidaemia in type 2 diabetes mellitus patients in Kuwait. Acta Diabetologica 41(3): 129-135.

23. Kandula R \& Shegokar VE (2013). A study of lipid profile in patients with type-2 diabetes mellitus. MRIMS $J$ of $H$ Sci 1(1): 23. 